\title{
DNA methylation is required for the control of stem cell differentiation in the small intestine
}

\author{
Karyn L. Sheaffer, ${ }_{1}^{1}$ Rinho Kim, ${ }^{1}$ Reina Aoki, ${ }^{1}$ Ellen N. Elliott, ${ }^{1}$ Jonathan Schug, ${ }^{1}$ Lukas Burger, ${ }^{2,3}$ \\ Dirk Schübeler, ${ }^{2,4}$ and Klaus H. Kaestner ${ }^{1,5}$ \\ ${ }^{1}$ Department of Genetics, Institute for Diabetes, Obesity, and Metabolism, Perelman School of Medicine, University of \\ Pennsylvania, Philadelphia, Pennsylvania 19104, USA; ${ }^{2}$ Friedrich Miescher Institute for Biomedical Research, 4058 Basel, \\ Switzerland; ${ }^{3}$ Swiss Institute of Bioinformatics, 4058 Basel, Switzerland; ${ }^{4}$ Faculty of Science, University of Basel, 4056 Basel, \\ Switzerland
}

The mammalian intestinal epithelium has a unique organization in which crypts harboring stem cells produce progenitors and finally clonal populations of differentiated cells. Remarkably, the epithelium is replaced every 3-5 d throughout adult life. Disrupted maintenance of the intricate balance of proliferation and differentiation leads to loss of epithelial integrity or barrier function or to cancer. There is a tight correlation between the epigenetic status of genes and expression changes during differentiation; however, the mechanism of how changes in DNA methylation direct gene expression and the progression from stem cells to their differentiated descendants is unclear. Using conditional gene ablation of the maintenance methyltransferase Dnmt1, we demonstrate that reducing DNA methylation causes intestinal crypt expansion in vivo. Determination of the base-resolution DNA methylome in intestinal stem cells and their differentiated descendants shows that DNA methylation is dynamic at enhancers, which are often associated with genes important for both stem cell maintenance and differentiation. We establish that the loss of DNA methylation at intestinal stem cell gene enhancers causes inappropriate gene expression and delayed differentiation.

[Keywords: DNA methylation; intestinal stem cell; Dnmt1]

Supplemental material is available for this article.

Received September 6, 2013; revised version accepted February 7, 2014.

The intestinal epithelium tightly regulates proliferation and differentiation in space and time and must maintain this control over thousands of cell divisions throughout life for organismal health. The small intestinal epithelium has a unique organization, with crypts harboring stem cells, which produce progenitors (transit-amplifying cells), and finally clonal populations of differentiated cells that migrate in ordered cohorts up the crypt-villus axis (Sheaffer and Kaestner 2012). The intestinal epithelium maintains this "self-renewal" capacity through the function of both quiescent and fast-cycling stem cells (Yeung et al. 2011). Crypt base columnar (CBC) stem cells are fast cycling, express LGR5, and are responsive to Wnt signaling (Barker et al. 2007). These cells are bona fide stem

${ }^{5}$ Corresponding author

E-mail kaestner@mail.med.upenn.edu

Article is online at http://www.genesdev.org/cgi/doi/10.1101/gad.230318.113. cells that can be isolated and form intestinal enteroids in vitro that self-renew and differentiate into all functional intestinal cell types (Barker et al. 2007). Excessive activation of Wnt signaling by disruption of APC specifically in $\mathrm{CBC}$ stem cells increases proliferation and causes formation of adenomas (Barker et al. 2009).

DNA methylation is critical for the regulation of gene expression during differentiation in many self-renewing tissues, including the germline and embryonic, hematopoietic, and epidermal stem cells (Sen et al. 2010; Smith and Meissner 2013). DNA methylation patterns are established and maintained by the de novo DNA

(C) 2014 Sheaffer et al. This article is distributed exclusively by Cold Spring Harbor Laboratory Press for the first six months after the full-issue publication date (see http://genesdev.cshlp.org/site/misc/terms.xhtml). After six months, it is available under a Creative Commons License (Attribution-NonCommercial 4.0 International), as described at http:// creativecommons.org/licenses/by-nc/4.0/. 
methyltransferases Dnmt3a and Dnmt3b and the maintenance methyltransferase Dnmt1, respectively. Dmnt1 is required for both differentiation and self-renewal in embryonic and adult stem cells (Lei et al. 1996; Lee et al. 2001; Broske et al. 2009; Trowbridge et al. 2009; Sen et al. 2010). Comparison of DNA methylation patterns in human embryonic stem cells (ESCs) and differentiated fetal fibroblasts at the genome-wide level revealed differential methylation at genes important for stem cell maintenance and differentiation processes (Lister et al. 2009). DNA demethylation at enhancers and promoters is correlated with priming and activation of lineage-specific genes at the appropriate time during development (Palacios et al. 2010). Conversely, promoters involved in stem cell gene expression frequently become more methylated as cells differentiate (Kim et al. 2010a; Polo et al. 2010; Schmidt et al. 2012). These studies show that DNA methylation is important in multiple differentiation systems; however, the function of DNA methylation in intestinal epithelial differentiation has not been evaluated.

We hypothesized that differential DNA methylation contributes to intestinal epithelial differentiation and function and therefore set out to determine the contribution of DNA methylation during adult intestinal stem cell (ISC) differentiation. Reduction of DNA methylation maintenance by acute deletion of Dnmt1 in the intestinal epithelium caused crypt expansion and decreased differentiation. Using whole-genome shotgun bisulfite sequencing (WGSBS), we show that DNA methylation is dynamic during the rapid transition from stem to the fully mature, differentiated epithelial cells. Our study reveals that the expression of important intestine-specific genes depends on methylation status and that Dnmt1 contributes to the timely repression of ISC genes during differentiation in vivo.

\section{Results}

As the first step in our investigation of the potential contribution of DNA methylation to intestinal proliferation and differentiation, we determined the expression patterns of all three DNA methyltransferases in the adult mouse intestine. Dnmtl was restricted to the crypts (Supplemental Fig. 1A; Suetake et al. 2001), while Dnmt3a was expressed throughout the epithelium, with higher expression in crypts (Supplemental Fig. 1B). Overall, Dnmt1 and Dnmt3a mRNA expression levels in the intestinal epithelium were even higher than those found in ESCs, where methyltransferases are known to be required for the establishment and preservation of DNA methylation of imprinted loci, repetitive elements, and tissue-specific CpG islands (Supplemental Fig. 1D; Li et al. 1992; Okano et al. 1999; Liang et al. 2002; Hattori et al. 2004). In contrast, only minimal levels of Dnmt3b protein were present in the intestine, confirming previous observations in colonic crypts (Supplemental Fig. 1C; Steine et al. 2011). In addition, Dnmt3b mRNA levels were fivefold lower in the intestinal epithelium than in ESCs (Supplemental Fig. 1D). We conclude that cells in the crypt zone, including stem and progenitor cells, express high levels of Dnmt1 and Dnmt3a, suggesting that both maintenance and de novo DNA methylation might be required in the proliferative compartment of the gut.

Next, we tested the hypothesis that methylation plays a role in the timing of differentiation using genetic means. Germline deletion of Dnmt1 in mice causes a $66 \%$ decrease in global methylation levels and embryonic lethality (Li et al. 1992). To avoid developmental defects, we used Dnmt $1^{10 x / l o x}$; Villin-Cre-ERT2 mice to inducibly delete Dnmt1 in the adult gut epithelium. Six days after intraperitoneal tamoxifen administration, all Dnmt1 gene expression was efficiently extinguished in the adult mouse small intestinal epithelium of $D n m t 1^{\text {lox } / l o x}$; Villin-Cre-ERT2 (mutant) compared with tamoxifentreated Dnmt $1^{\text {lox/lox }}$ (control) mice (Fig. 1A,B). Deletion was achieved throughout the entire length of the intestine and was confirmed by quantitative RT-PCR (qRT-PCR), with mutants showing a $90 \%$ reduction of Dnmt 1 mRNA levels (Fig. 1C).

The acute deletion of Dnmt1 caused a modest but statistically significant expansion of the small intestinal crypt zone. The crypt zone, designated by the proliferation marker Ki67, was expanded twofold in mutant mice (Fig. 1D-F) and exhibited increased expression of the Wntresponsive ISC genes Sox9 and Msi1 (Fig. 1G-I; Supplemental Fig. 2G,H; Potten et al. 2003; Formeister et al. 2009). In addition, we observed a corresponding decrease in steady-state mRNA levels of the differentiated enterocyte markers alkaline phosphatase (AP) and lactase (Lct) (Stegmann et al. 2006) as well as a decreased AP-positive domain in the crypt-villus axis (Fig. 1J-L). Interestingly, cell fate decisions among differentiating cells were largely unaffected by the loss of Dnmt1, as the proportion of the differentiated cell types, including enteroendocrine, goblet, and Paneth cells, stayed constant (Supplemental Fig. 2A-F). However, increased numbers of secretory progenitor cells were found above the crypt base with goblet cell morphology and lysozyme expression, suggesting a partial disruption in secretory cell specification (Supplemental Fig. 2F; Schneider et al. 2010).

Having established that DNA methylation is required for intestinal crypt homeostasis, we determined baseresolution DNA methylomes of ISCs and differentiated cells in the small intestine in order to begin to investigate the molecular defects underlying the observed mutant phenotype. We separated stem cells and their immediate, proliferating daughters using fluorescent-activated cell sorting (FACS) for green fluorescent protein (GFP) in Lgr5EGFP-ires-CreERT2 transgenic mice, as previously described (van der Flier and Clevers 2009; Munoz et al. 2012). Highly enriched differentiated villous epithelial cell fractions were collected by EDTA dissociation and gentle scraping. The villous cell fractions contained terminally differentiated intestinal epithelial cells, the majority of which are enterocytes, as well as goblet and enteroendocrine cells (van der Flier and Clevers 2009). Confirmation of cell purity was performed by qRT-PCR for the stem cell-specific marker Lgr5, the proliferation marker Ki67, and the enterocyte marker Lct (Supplemental Fig. 3A). DNA extracted from the LGR5 ${ }^{+}$stem and 

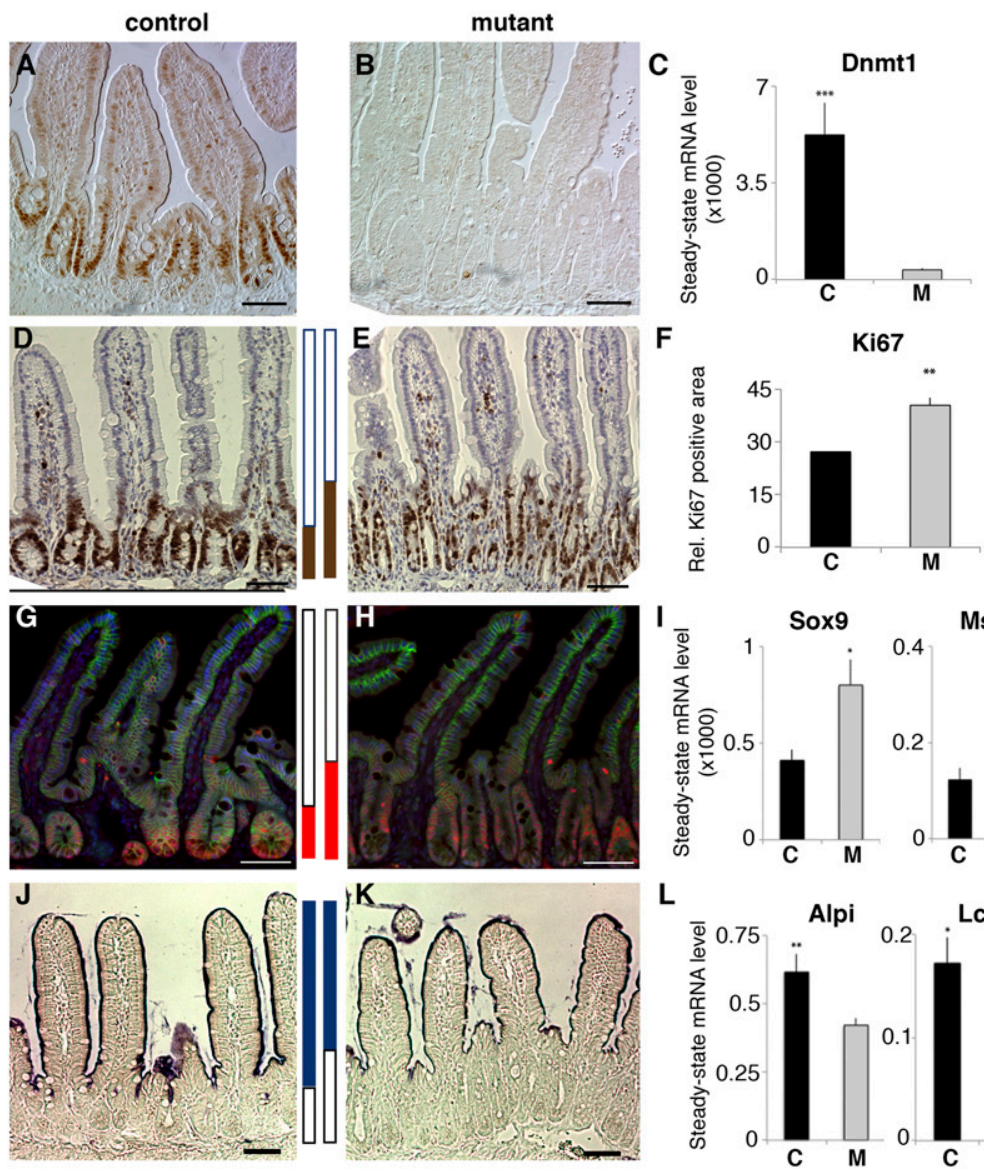

Figure 1. Conditional ablation of DNMT1 in vivo causes crypt expansion. $(A, B)$ Immunohistochemical staining of Dnmt1 protein in Dnmt1 $1^{\text {lox/lox }}$ (control) $(A)$ and Dnmt1 $1^{\text {lox/lox }}$; Villin-Cre-ERT2 (mutant) $(B)$ mice. Dnmt1 protein is absent from the adult mouse small intestinal epithelium $6 \mathrm{~d}$ after tamoxifen treatment. Bars, $50 \mu \mathrm{m}$. (C) Dnmt1 mRNA expression by qRT-PCR shows a $90 \%$ decrease in the mutant intestinal epithelium. mRNA levels are expressed relative to those of Gapdh. Mean $\left.\pm \mathrm{SE} ; n \geq 11_{;}{\left({ }^{\star \star}\right)}^{*}\right)<$ 0.001 by $t$-test. $(D, E)$ Immunohistochemical staining of Ki67 shows an increased number of proliferative crypt cells in the mutant $(E)$ intestinal epithelium compared with control $(D)$. $(F)$ Quantification of the Ki67-positive area (percentage relative to villous height). Mean $\pm \mathrm{SE}$; $\left.n=4 ;{ }^{\star \star}\right) P<0.01$ by $t$-test. $(G, H)$ Immunofluorescence staining of Sox9 (red) and E-cadherin (green) shows an increased number of undifferentiated crypt cells in the mutant $(H)$ intestinal epithelium compared with control $(G)$. Nuclei were stained with DAPI. (I) SRY-box9 (Sox9) and Musashil (Msil) mRNA expression analysis by qRT-PCR shows increased expression of ISC genes in mutant intestinal epithelial crypt cells. mRNA levels are expressed relative to those of Gapdh. Mean $\pm \mathrm{SE} ; n \geq 4 ;\left(^{\star}\right) P<0.05$ by $t$-test. $(J, K)$ AP staining in control $(J)$ and mutant $(K)$ intestines. Mutants show decreased area of APpositive cells. ( $L$ ) AP (Alpi) and Lct mRNA expression by qRT-PCR shows decreased enterocyte markers in mutant intestinal epithelium villous cells. mRNA levels are expressed relative to those of Gapdh. Mean $\pm \mathrm{SE} ; n \geq 6 ;\left(^{\star}\right) P<0.05$; $\left.{ }^{\star \star}\right) P<0.01$ by $t$-test.

differentiated cell populations from a pooled cohort of five or two mice, respectively, were used for genome-wide analysis of DNA methylation, and three independent biological replicates from each of the two cell populations were used for mRNA expression analysis.

To obtain single-base-pair resolution of DNA methylation in intestinal $\mathrm{LGR}^{+}$stem and differentiated epithelial cells, we used WGSBS. Genomic sequencing cumulative coverage for LGR $5^{+}$and differentiated cells was an average of 26-fold and 20-fold, respectively (Supplemental Fig. 4A). We observed little non-CpG methylation across the genome for both cell populations (Supplemental Fig. 4B). Similar to observations from the first published base-resolution methylome of mouse ESCs, promoters were hypomethylated, while the remainder of the genome was highly methylated in the intestinal genome (Supplemental Fig. 4C; Stadler et al. 2011).

We segmented both intestinal methylomes into three classes: fully methylated regions (FMRs; $>50 \%$ methylated CpGs), low-methylated regions (LMRs; $13.9 \%-50 \%$ ), and unmethylated regions (UMRs; $<13.9 \%$ ), as previously described (Stadler et al. 2011). We found an increased number of LMRs in differentiated cells compared with ISCs, covering an area of $>9 \mathrm{Mb}$, possibly reflecting areas of active demethylation (Supplemental Fig. 4D). As observed previously, $\mathrm{CpG}$ islands across the genome were highly enriched for UMRs in both LGR5 ${ }^{+}$stem and differentiated cells (Fig. 2A; Supplemental Fig. 5A,B; Stadler et al. 2011). While only $0.4 \%$ of the mouse genome is located in CpG islands ("Genome" in Fig. 2A), 20\% of UMRs in both LGR5 stem and differentiated cells are at CpG islands (Fig. 2A). Likewise, CpG shores make up only $2.4 \%$ of the mouse genome but represent $29.8 \%$ and $34.4 \%$ of LGR5 stem and differentiated cell UMRs. In contrast, the fraction of LMRs (13.9\%-50\% CpG methylation) that mapped to $\mathrm{CpG}$ islands and CpG shores in both cell types is lower than expected from the genome-wide distribution of these features (Fig. 2A).

Comparison of $\mathrm{LGR}^{+}$stem and differentiated cell UMRs and LMRs using stringent statistical criteria (for details, see the Materials and Methods) revealed a total of 4240 regions covering $4.58 \mathrm{Mb}$, identified as differentially methylated regions (DMRs). Recently, Kaaij et al. (2013) reported very few DNA methylation changes during adult intestinal differentiation using a cutoff of a minimal differential methylation of $40 \%$. However, the majority of enhancer regions, defined by Stadler et al. (2011) as LMRs and containing $13.9 \%-50 \%$ methylation levels, were undetectable in their analysis. The average change in methylation state at DMRs during intestinal differentiation was 
A


shore other

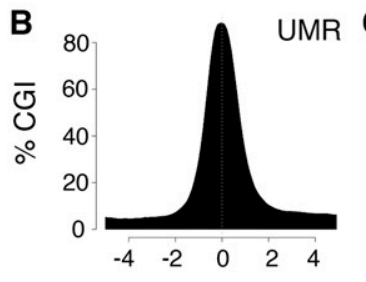

C

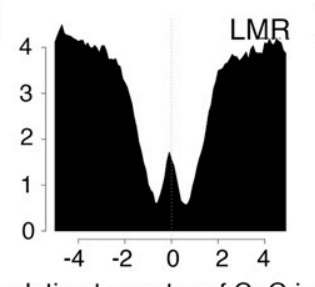

D
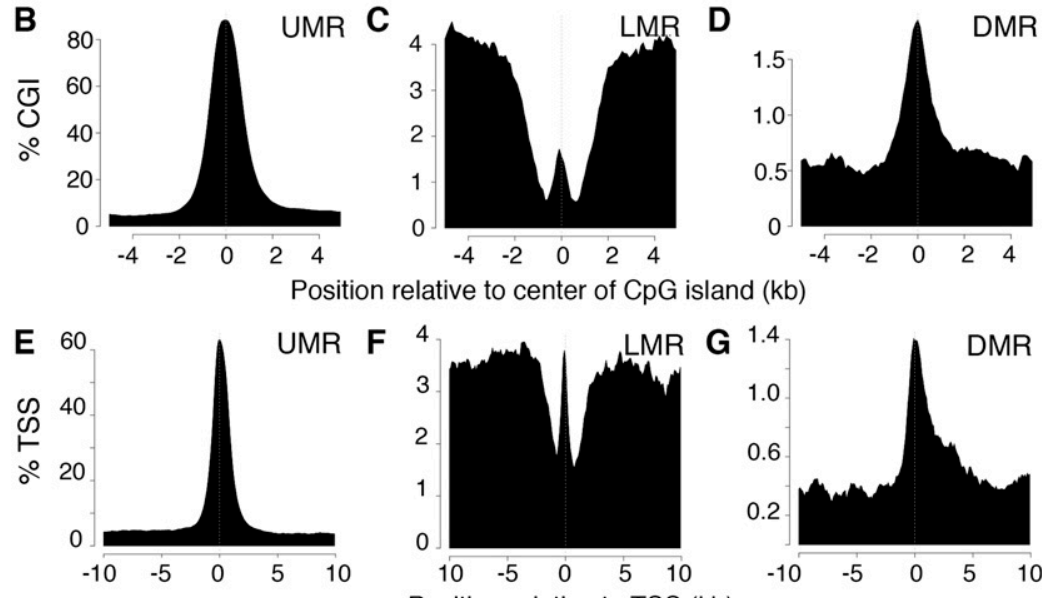

Position relative to TSS $(\mathrm{kb})$
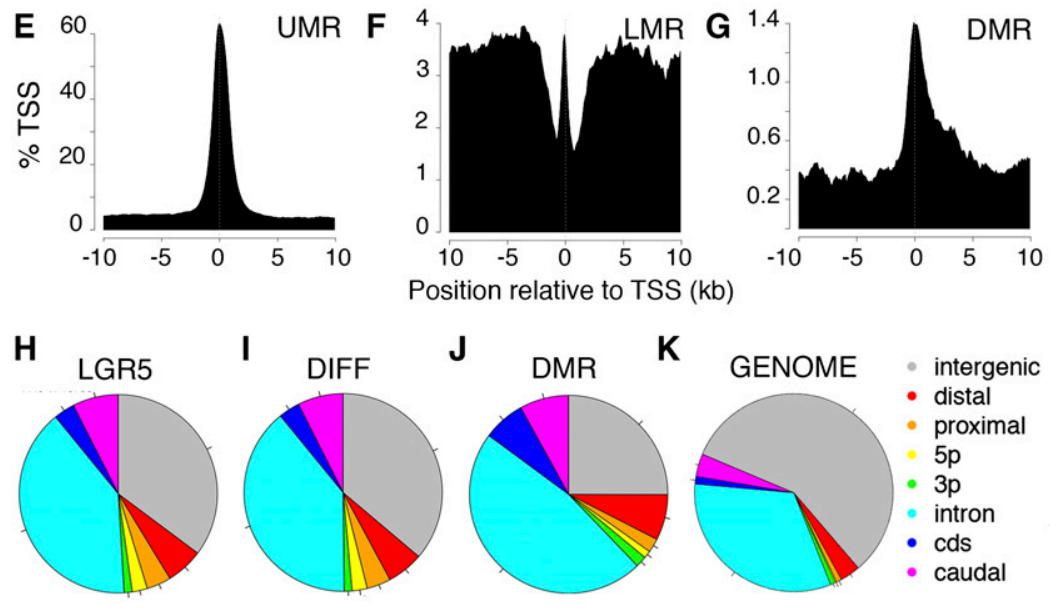

$\mathrm{K}$

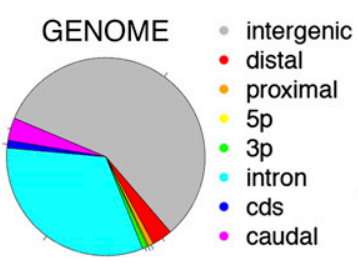

Figure 2. Dynamic changes in DNA methylation during intestinal differentiation. $(A)$ The percent of CpG islands (CGI; red), shores of CpG islands (blue), and the rest of the genome ("other"; yellow) compared with UMRs and LMRs in LGR $^{+}$cells and differentiated cells and in DMRs. CpG islands and shores constitute only a small portion $(0.4 \%$ and $2.4 \%)$ of the genome but are enriched in UMRs in both cells as well as (to a lesser extent) in DMRs. LMRs are typically found outside of $\mathrm{CpG}$ islands and shores. "Genome" indicates the percentage of the mappable mouse genome in each category. $(B-D)$ Positional analysis of UMRs, LMRs, and DMRs located within $\pm 5 \mathrm{~kb}$ of the center of a CpG island. In $\mathrm{LGR}^{+}$cells, UMRs $(D)$ are found enriched within $\mathrm{CpG}$ islands, and LMRs $(E)$ are excluded from CpG islands. (F) DMRs are found enriched within CpG islands. $(E-G)$ Positional analysis of UMRs, LMRs, and DMRs within $\pm 10 \mathrm{~kb}$ of the TSS. In LGR 5 cells, LGR5 ${ }^{+}$ $(E)$ are found enriched over the TSS, and LMRs $(F)$ are found excluded from the TSS. $(G)$ DMRs are enriched at the TSS and span over the proximal portion of the gene body (first exon and intron). $(H-K)$ Genomic regional analysis of all UMRs, LMRs, and DMRs. The majority UMRs and LMRs in in LGR5 $(H)$ and DIFF $(I)$ cells were found in introns and intergenic regions. (J/) DMRs were enriched in introns and distal promoters. $(K)$ The representation of the regions analyzed in the mouse genome. Regional definitions: proximal, 0 to $-1 \mathrm{~kb}$ from the TSS; distal, $-1 \mathrm{~kb}$ to $-5 \mathrm{~kb}$ from the TSS; caudal, $+5 \mathrm{~kb}$ from the end the of 3' UTR. $\sim 15 \%$. Interestingly, regions of differential methylation were overrepresented at both CpG islands $(4.4 \%$ vs. $0.4 \%$ in the genome) and CpG shores $(10.1 \%$ vs. $2.4 \%$ in the genome), suggesting that methylation changes frequently occur in genomic elements relevant to gene regulation (Fig. 2A).

A more detailed analysis of these methylome data revealed additional interesting points. When plotting the methylation classes UMR, LMR, and DMR relative to the center of CpG islands, as expected, $>80 \%$ of CpG islands coincide with UMRs (Fig. 2B). Conversely, LMRs are depleted at $\mathrm{CpG}$ islands, with increasing representation at $\mathrm{CpG}$ shores (Fig. 2C). Regions of differential methylation are enriched at CpG islands but to a much lesser extent than UMRs (Fig. 2D). A similar profile emerges when all transcriptional start sites (TSSs) are considered. The representation of UMRs is near $60 \%$ at TSSs, reflecting the fact that not all promoters are associated with CpG islands and not all UMRs are at TSSs (Fig. 2E). LMRs, in contrast to UMRs, are found mainly either upstream of the TSSs or within gene bodies, often within the first intron (Fig. 2F). Finally, DMRs show a peak at TSSs but also a strong shoulder within the first intron, where enhancers are frequently found in mammalian genes (Fig. 2G). When segmenting the entire genome into regions of interest, such as proximal and distal promoters, introns, and coding regions, one can visualize the fact that the vast majority of the genome is made up of intergenic and intronic regions (Fig. 2K). However, UMRs and LMRs in both the LGR $5^{+}$and differentiated cells are concentrated in likely regulatory regions, including introns (40\%), proximal $(4 \%)$ and distal promoters $(6 \%)$, and caudal regions $(7.5 \%)$, defined as the $5 \mathrm{~kb} 3^{\prime}$ to the end of each gene (Fig. 2H,I). Locations of DMRs were found to be enriched within introns $(47.3 \%)$ and distal promoters $(7.5 \%)$ (Fig. 2J). suggesting that DNA methylation changes are concentrated in regulatory regions, while other regions of the genome exhibit stable methylation patterns.

Global analysis of the DMRs identified above established that most UMRs gain methylation during differentiation (Fig. 3A), whereas LMRs show both gain and loss of methylation (Fig. 3B). Importantly, loss of methylation at DMRs located in regulatory regions, such as promoters, introns, and 3 ' untranslated regions (UTRs), correlates with higher expression of the associated gene in differentiated cells as compared with LGR $5^{+}$cells (Fig. 3C; Supplemental Fig. 6). Several lines of evidence suggest that intestine-specific DMRs are functionally relevant. First, DMRs located in regulatory regions such as distal promoters and introns showed average methylation gains of 

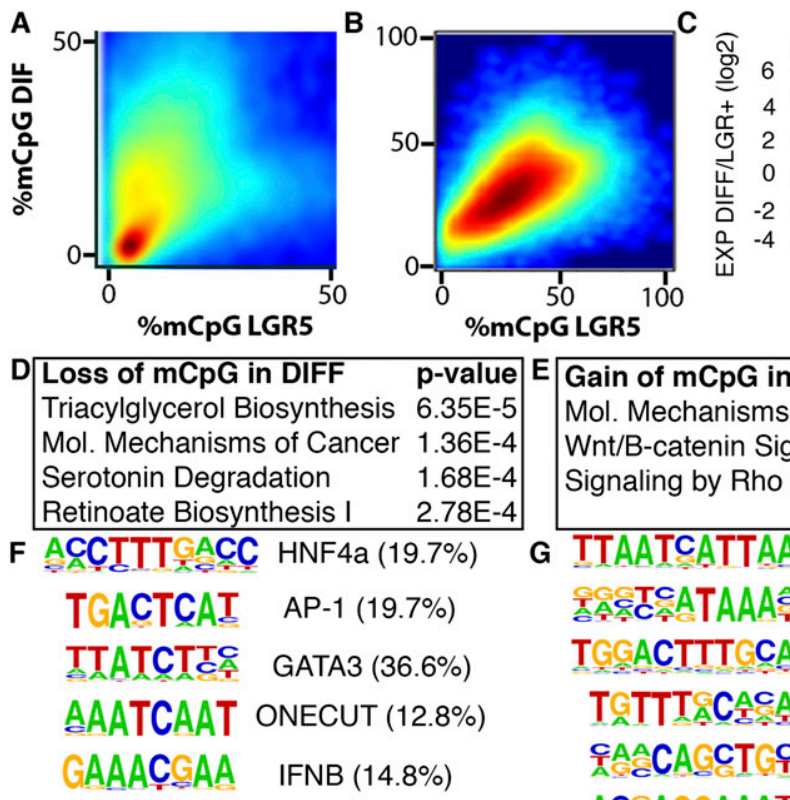

$E$

Gain of $\mathrm{mCpG}$ in DIFF

Mol Mechanisms Wnt/B-catenin Signaling 2.63E-6 Signaling by Rho GTPases $4.96 \mathrm{E}-6$

G ITAATCATTAAC HNF1 (10.3\%)

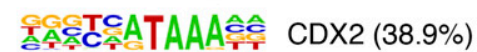
TGGACTTTGCAC HNF4a (27\%) TGTTT CAㅜㄹ수소 FOXA1 (23.8\%) 둣ACAGCTGC TCF12 (41.3\%)

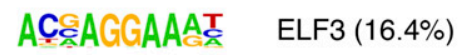

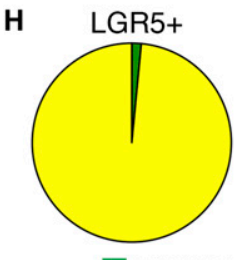

H3K27ac

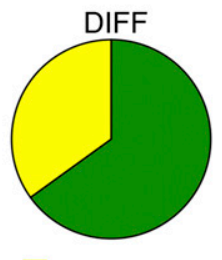

none

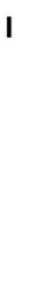





none

Figure 3. DMRs are associated with active intestinal enhancer regions. $(A, B)$ Comparison of DNA methylation of all UMRs $(A)$ or LMRs $(B)$ between LGR5 and DIFF cells (density [i.e., number of regions] increases from blue to red). Generally, UMRs show increased methylation in DIFF cells compared with LGR5 cells, while LMRs show methylation changes in both directions. $(C)$ Expression analysis of genes associated with DMRs located within promoter regions (5000 base pairs [bp] upstream of the TSS). DMRs that lose methylation correlate with higher gene expression in DIFF cells compared with DMRs that gain methylation. The whiskers of the box plot correspond to $10 \%$ and $90 \%$ of the distribution. $\left(^{\star \star \star}\right) P<0.001$ by $t$-test. $(D, E)$ Pathway analysis for genes associated with DMRs. (D) Genes associated with regions that lose methylation following differentiation show enrichment of metabolism genes that are expressed in differentiated cells. $(E)$ Regions that gain methylation in differentiated cells are associated with genes important for ISCs. $(F, G)$ De novo motif analysis of DMRs show that regions that lose methylation in differentiated cells $(F)$ are enriched in differentiation-specific transcription factor motifs, and regions that gain methylation in differentiated cells $(G)$ are enriched in ISC transcription factor motifs. Percentage reflects the fraction of regions that were found with each motif within the specific group of DMRs. $(H, I)$ Percentage of DMRs that lose DNA methylation $(H)$ or gain methylation $(I)$ that show overlap with regions that contain H3K27ac in either LGR5 or DIFF cells. (H) DMRs that lose methylation during differentiation show a dramatic gain in H3K27ac (LGR5: 2\%; DIFF: 65\%). (I) DMRs that gain methylation are marked with H3K27ac in both LGR5 and DIFF cells (LGR5: 59\%; DIFF: 71\%).

$13.3 \%$ and $14.2 \%$, respectively (data not shown). Conversely, DMRs located at promoters had a significantly lower mean gain of $8.5 \%$ methylation (data not shown). These data reveal that methylation gain during differentiation is not a general phenomenon across all UMRs of the genome but is targeted to likely enhancer regions. Second, DMRs that lose methylation during differentiation were associated with genes involved in important aspects of small intestine enterocyte metabolism, including "triglyceride biosynthesis," "serotonin metabolism," and "retinol biosynthesis" (Fig. 3D; see Supplemental Fig. 3C for a full list of statistically significant pathways; Gershon 2004; Harrison 2005; Pan and Hussain 2012). Strikingly, motif finding analysis revealed that these regions are enriched for binding sites of multiple factors required for intestinal epithelial differentiation, including HNF-4 $\alpha$ (Garrison et al. 2006), Onecut (Dusing et al. 2010), and GATA (Fig. 3F; Beuling et al. 2011). In order to further investigate the possible role for dynamic methylation at relevant regulatory elements, we performed chromatin immunoprecipitation (ChIP) combined with deep sequencing (ChIP-seq) for the active enhancer mark H3K27ac in both LGR $^{+}$stem and differentiated cell populations (Supplemental Fig. 4A). DMRs that lost methylation during differentiation showed a dramatic gain of $\mathrm{H} 3 \mathrm{~K} 27 \mathrm{ac}$ in differentiated cells (Fig. $3 \mathrm{H})$, suggesting that loss of DNA methylation is associated with activation of specific enhancers during the differentiation process.

In contrast, DMRs that gained methylation during differentiation were associated with genes involved in signaling pathways of established importance in ISCs, including the Wnt/Bcatenin and Rho family GTPase pathways (Fig. 3E; see Supplemental Fig. 3C for full list of statistically significant pathways; Stappenbeck and Gordon 2000; Sakamori et al. 2012; Schepers and Clevers 2012). Interestingly, these latter regions are enriched for binding sites of factors required for ISC maintenance and differentiation, including HNF-1 $\alpha$ (D'Angelo et al. 2010; Lussier et al. 2010), CDX2 (Gao et al. 2009; Gao and Kaestner 2010; Verzi et al. 2011), and FOXA1 (Fig. 3G; Ye and Kaestner 2009). Surprisingly, the majority of these regions were marked by H3K27ac in both LGR $^{+}$stem and differentiated cells, suggesting that gain of DNA methylation at these sites is not sufficient to alter this histone mark (Fig. 3I).

Next, we used mRNA sequencing to determine the gene expression profile of LGR $5^{+}$stem and differentiated cell populations. We observed high levels of expression for the expected stem cell and enterocyte-specific genes in $\mathrm{LGR}^{+}$stem and differentiated cell populations, re- 
spectively (Supplemental Fig. 3B). Genes that were highly expressed in the villous cell population were designated as "differentiation-induced genes." Because the LGR5 ${ }^{+}$ cell population is made up of both stem cells and their immediate daughter cells, we used the previously published ISC RNA signature (Munoz et al. 2012) to separate "ISC genes" from "progenitor genes" in our data set. Using this approach, we identified 1093 genes that were highly expressed in the LGR $5^{+}$population that have not been previously characterized as ISC-specific genes, which we therefore defined as "progenitor genes" (Supplemental Table 1).

To investigate the relationship between differential expression and differential DNA methylation of nearby regulatory elements in the intestinal epithelium differentiation process, we integrated our DNA methylation and gene expression data sets. We found that 128 of the 384 ISC-specific expressed genes are associated with regions that gained methylation during differentiation, suggesting that extinction of the ISC signature in differentiated cells is at least partially driven by de novo methylation (Supplemental Table 2). Strikingly, the vast majority of these DMRs $(73.7 \%)$ were located in introns. These genes include well-characterized CBC stem cell genes such as Lgr5, AscI2, and Olfm4, which exhibited one to three DMRs (Fig. 4A). We verified important DMRs identified by WGSBS using targeted bisulfite sequencing in three biological replicates each of differentiated and LGR $5^{+}$stem cells. Methylation levels of individual CpGs contained within DMRs associated with Olfm4 (Fig. 4B), Hes1 (Fig. 4C), and Lct (Fig. 4D), while not significantly increased at each individual $\mathrm{CpG}$, on average showed methylation gains similar to those that we had observed by WGSBS. As a control, we analyzed the imprinted locus H19 by pyrosequencing, which exhibited constant methylation during intestinal differentiation, demonstrating that the methylation changes between the LGR $5^{+}$and differentiated cells are specific to
A ISC genes

\begin{tabular}{|c|c|c|c|c|c|}
\hline Gene & \#DMRS & avg $\triangle \% \mathrm{mCpG}$ & $p$-value & mRNA fold $\Delta$ & $p$-value \\
\hline Lgr5 & 2 & 13.8 & $2.7 \mathrm{E}-33$ & -7.2 & $6.2 \mathrm{E}-04$ \\
\hline Ascl2 & 1 & 12.2 & $5.8 \mathrm{E}-12$ & -6.5 & $1.9 \mathrm{E}-04$ \\
\hline Olfm4 & 3 & 12.2 & $2.0 \mathrm{E}-44$ & -5.1 & $1.0 \mathrm{E}-11$ \\
\hline \multicolumn{6}{|c|}{ Progenitor genes } \\
\hline Gene & \#DMRS & avg $\triangle \% m C p G$ & p-value & mRNA fold $\Delta$ & $p$-value \\
\hline Bmp7 & 1 & 32.6 & $3.2 \mathrm{E}-08$ & -5.5 & $1.2 \mathrm{E}-02$ \\
\hline Ephb2 & 5 & 10.4 & $3.6 \mathrm{E}-06$ & -3.3 & $1.2 \mathrm{E}-04$ \\
\hline Hes1 & 3 & 13.2 & $1.0 \mathrm{E}-29$ & -2.4 & 4.3E-03 \\
\hline
\end{tabular}

Differentiation-induced genes

\begin{tabular}{|c|c|c|c|c|c|}
\hline Gene & \#DMRS & avg $\Delta \%$ mCpG & p-value & mRNA fold $\Delta$ & p-value \\
\hline Lct & 1 & -36.3 & $1.2 \mathrm{E}-11$ & 7.7 & $4.4 \mathrm{E}-16$ \\
\hline Alpi & 2 & -45.0 & $2.6 \mathrm{E}-18$ & 7.4 & $2.1 \mathrm{E}-11$ \\
\hline Krt20 & 1 & -40.7 & $1.6 \mathrm{E}-08$ & 7.3 & $8.6 \mathrm{E}-06$ \\
\hline
\end{tabular}

B

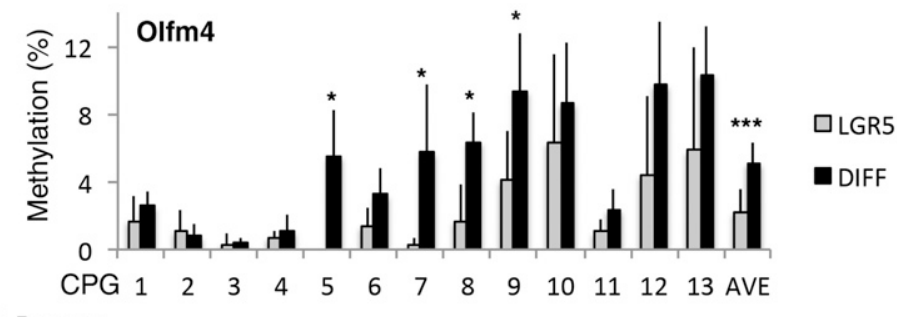

C

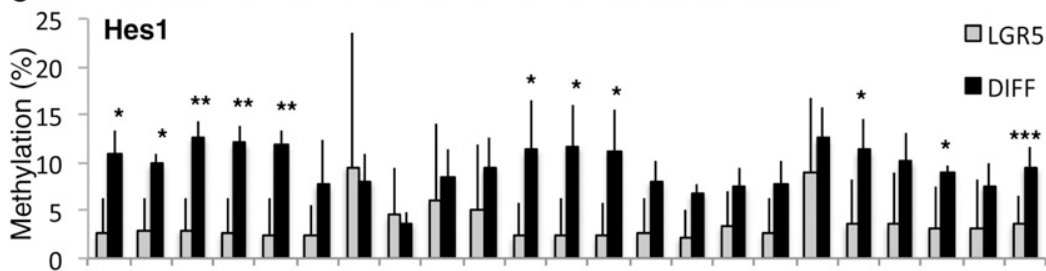

$\begin{array}{lllllllllllllllllllllll}\text { D CPG1 } & 2 & 3 & 4 & 5 & 6 & 7 & 8 & 9 & 10 & 11 & 12 & 13 & 14 & 15 & 16 & 17 & 18 & 19 & 20 & 21 & 22 & \text { AVE }\end{array}$

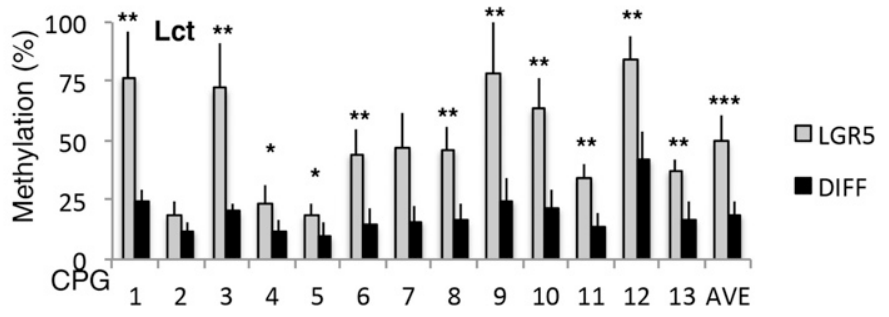

Figure 4. DMRs are associated with intestinalspecific genes and correlate with expression during differentiation. (A) Partial list of genes with differential mRNA expression and associated DMRs in LGR5 ${ }^{+}$stem cells compared with differentiated cells. Transcripts with increased expression in LGR $5^{+}$stem cells were categorized as ISC genes or progenitor genes as described in the text. Transcripts with increased expression in villous cells were categorized as differentiationinduced genes. Genes are listed with the number of associated DMRs, average change in methylation (DIFF-LGR5) and corresponding $P$-value, and mRNA fold change (DIFF-LGR5) and corresponding $P$-value. $(B-D)$ Verification of DMRs by bisulfite sequencing. Three biological replicates of LGR5 $^{+}$and DIFF cells were used to verify identified DMRs by targeted bisulfite sequencing to determine methylation at the single-CpG level and regional average. DIFF cells show increased regional average methylation at the DMRs associated with Olfm4 (LGR5: $2.2 \% \pm$ $1.4 \%$; DIFF: $5.1 \% \pm 1.2 \%)(B)$ and Hes1 (LGR5: $3.7 \% \pm 2.9 \%$; DIFF: $9.5 \% \pm 2.1 \%)(C)$. (D) DIFF cells show decreased regional average methylation at the DMR associated with Lct (LGR5: $49.8 \% \pm 10.5 \%$; DIFF: $\left.18.9 \% \pm 5.9 \%) .{ }^{*}\right) P<$ $\left.\left.0.05 ;\left.\right|^{\star \star}\right) P<0.01 ;\left.\right|^{\star \star \star}\right) P<0.001$ by $t$-test. 
DMRs (Supplemental Fig. 7A). Pathway analysis showed this group of 128 ISC signature genes to be enriched for Wnt/ $\beta$ catenin and TGF $\beta$ signaling, supporting the notion that these genes maintain a low-methylation status in ISCs and progenitor cells (Fig. 5A; Supplemental Fig. 3D shows all significant gene categories).

Of the 1093 "progenitor" genes defined above, we found that 140 gained methylation during differentiation (Supplemental Table 3). Among this group were genes important for directing differentiation, such as $B m p 7, E p h b 2$, and Hes1 (Fig. 4A). More globally, the 140 progenitor genes with increased methylation after differentiation were enriched for functional categories such as "translation initiation" and "Notch signaling," pathways known to be critical for proliferation and differentiation (Fig. 5C; Supplemental Fig. 3D shows all significant gene categories; Duranton et al. 1998; Wang et al. 2012; Noah and Shroyer 2013). Finally, 523 out of 3758 "differentiation-induced" genes, highly expressed in villous cells, showed decreased methylation after differentiation and included enterocyte-specific genes such as Lct, Alpi, and Krt20 (Fig. 4A). The majority of DMRs $(61 \%)$ that lost methylation were found located in introns. This group was enriched for genes important for enterocyte metabolic functions and immune response such as "triacylglycerol biosynthesis" and "iNOS signaling" (Fig. 5E; Supplemental Fig. 3D shows all significant gene categories; Supplemental Table 4; Cavicchi and Whittle 1999; Pan and Hussain 2012).

Strikingly, DMRs associated with differential gene expression showed dynamic association with H3K27ac during differentiation. A proportion of ISC genes that gained DNA methylation during differentiation also lost H3K27ac (Fig. 5B). In contrast, progenitor genes that gained methylation had no change in H3K27ac (Fig. 5D). Strikingly, the vast majority of DMRs that lost methylation during differentiation acquired H3K27ac (Fig. 5E). To determine which regions were indeed active enhancers bound by intestinal transcription factors, we compared the differentiation-specific regions that lost methylation with previously published binding profiles for $\mathrm{Cdx} 2$ and Hnf4 $\alpha$ from villous cells (Verzi et al. 2013). Remarkably, we found that $70 \%$ of these regions are bound by one or both of these factors (Fig. 5G). Interestingly, genes with increased methylation in differentiated cells cover a spectrum of ISC factors, suggesting that DNA methylation coordinates the shutdown of multiple ISC-specific pathways during differentiation. To explore this notion further, we examined two genes that are important for stem cell maintenance, Olfm4 and Hes1, in more detail.

Olfm4 was exclusively expressed in LGR $5^{+}$ISCs and gained methylation at multiple sites during differentiation. Olfm4 has DMRs located at $19 \mathrm{~kb}$ and $14 \mathrm{~kb}$ upstream of the TSS that gained $14 \%$ and $10 \%$ methylation, respectively, as LGR5 ${ }^{+}$stem cells differentiate (Fig. 6A). A third large DMR gained $12 \%$ methylation, is located over the Olfm4 proximal promoter, and extends into the first half of the coding region of the gene (Fig. 6A). To our knowledge, nothing is currently known about the role of distal enhancer elements in the regulation of Olfm4

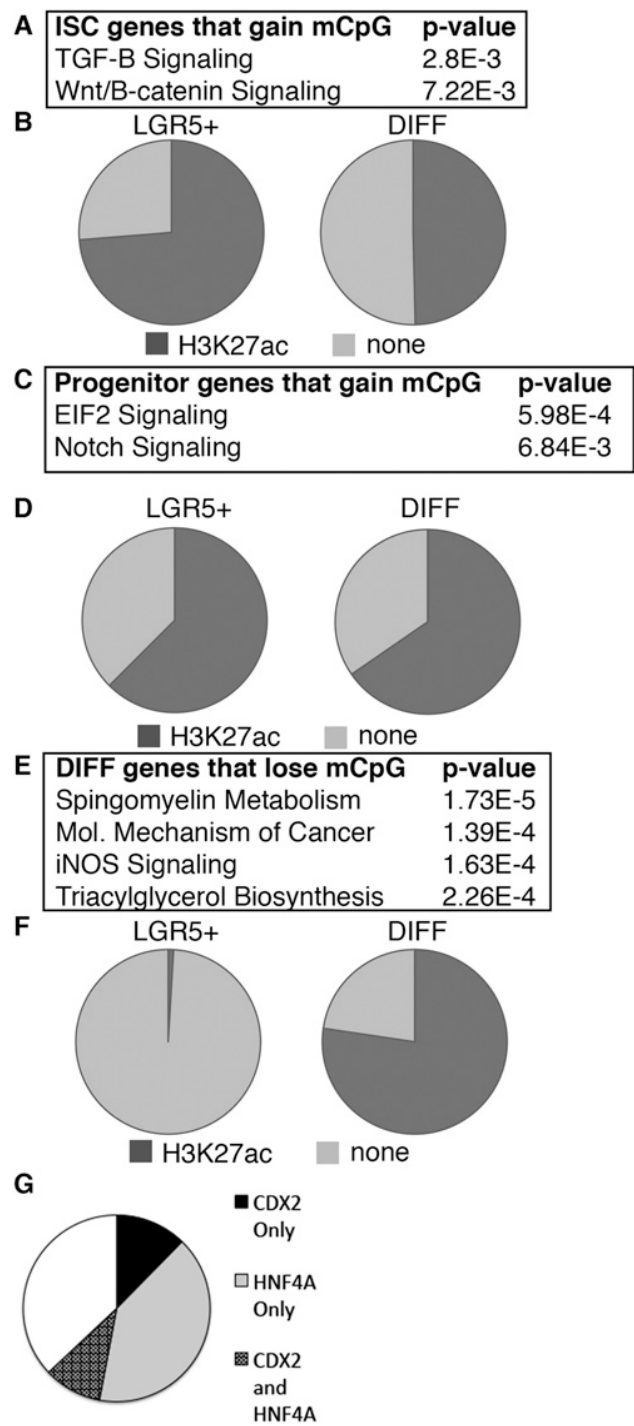

Figure 5. Differentially methylated genes are associated with transcription factor binding. $(A, C, E)$ Pathway analysis of ISC $(A)$, progenitor $(C)$, and differentiation-induced $(E)$ genes associated with DMRs. $(B, D, F)$ Overlap of the H3K27ac enhancer mark in LGR $^{+}$and DIFF cells and DMRs found associated with ISC genes $(B)$, progenitor genes $(D)$, and differentiation genes $(F)$. ISC DMRs are more highly enriched for the H3K27ac mark in LGR5 cells (LGR5: 74\%; DIFF: 55\%). DIFF DMRs are more highly enriched for the H3K27ac mark in the DIFF cells (LGR5: 0.9\%; DIFF: $77 \%$ ). Progenitor DMRs show little change between LGR5 and DIFF cells (LGR5: 63\%; DIFF: 65\%). (G) Overlap of CDX2 and HNF4 $\alpha$ Chip-seq peaks (Verzi et al. 2013) with DMRs found associated with differentiation genes. The majority of DMRs $(72 \%)$ show binding of $\mathrm{HNF} 4 \alpha$ and CDX2, suggesting enhancer activity.

expression. However, there are multiple transcription factor-binding sites in the proximal promoter important for Olfm4 expression, including nuclear factor- $\mathrm{kB}$ (NF-кB) (Huang et al. 2010; Kim et al. 2010b) and RBP-J, the main transcriptional mediator of Notch signaling (VanDussen et al. 2012). In the DMR at the proximal promoter, CpGs are directly adjacent to the NFкB- and predicted RBP-J- 


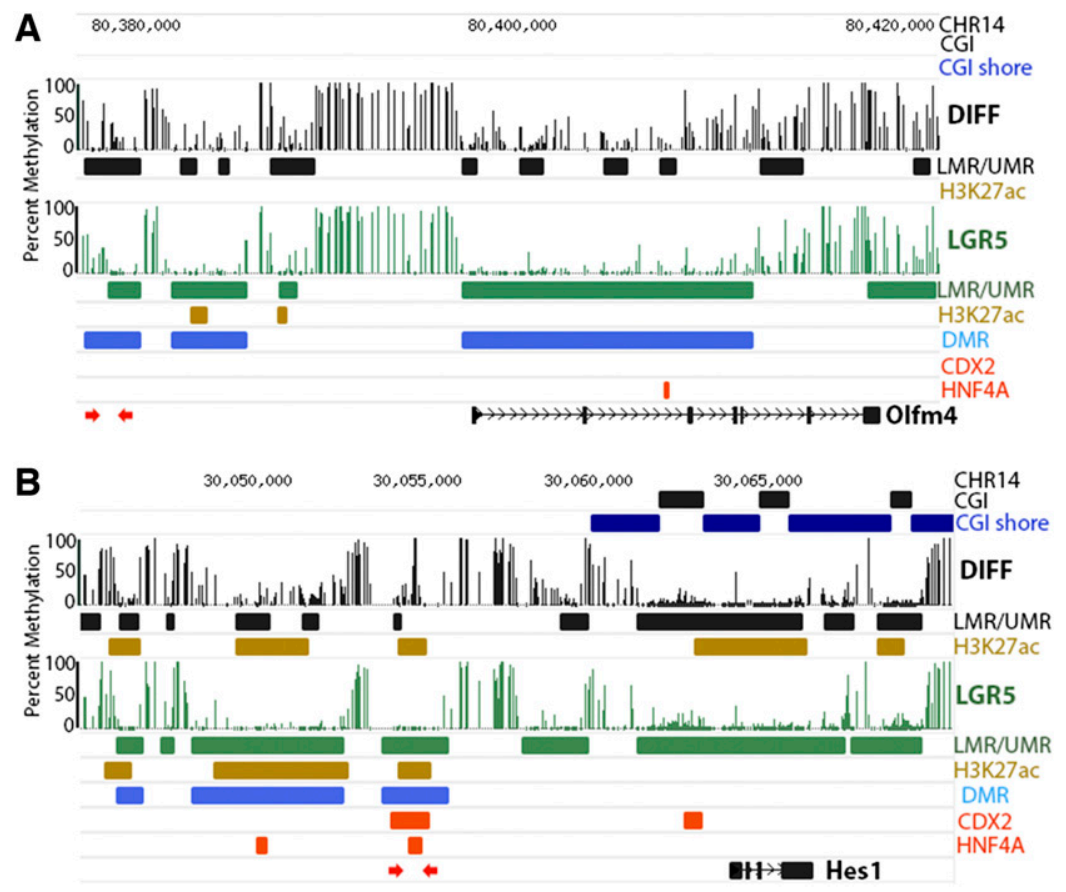

Figure 6. DNA methylation correlated with gene activity of Olfm4 and Hes1. Comparison of DNA methylation status between LGR $5^{+}$and DIFF cells at the ISC-specific gene Olfm $4(A)$ and the progenitor-specific gene Hes1 $(B)$. Bars represent percent methylation at individual CpGs in differentiated cells (black) and LGR ${ }^{+}$stem cells (green). UMRs and LMRs for differentiated cells (black bars) and LGR5 ${ }^{+}$stem cells (green bars) as well as DMRs (blue bars) are designated. CpG islands (CGI), CpG island $\pm 2 \mathrm{~kb}$ (CGI shores), ChIP-seq peaks for H3K27ac (yellow), CDX2 (red), and HNF4A (red) are also indicated. Red arrows mark regions that were independently verified by region-specific bisulfite sequencing. binding sites. Additionally, we found that the H3K27ac chromatin mark of active enhancers associated with one of the distal DMRs in LGR5 ${ }^{+}$cells (Fig. 6A). The H3K27ac mark is present at this enhancer in LGR $5^{+}$stem cells but is lost after differentiation. Previously, DNA methylation had also been correlated with OLFM4 expression in human cancer, and the proximal DMR that we identified in the mouse Olfm4 gene contains six of the eight corresponding CpGs of the human promoter that are important for cancer-induced expression through retinoic acid signaling (Liu et al. 2010).

We found Hes1, a gene critical for both proliferation and differentiation of intestinal epithelia, to be highly expressed in both stem and progenitor cells (Ueo et al. 2012). We identified DMRs with methylation gain after differentiation located at $17 \mathrm{~kb}, 13 \mathrm{~kb}$, and $9 \mathrm{~kb}$ upstream of the Hes1 TSS (Fig. 6B). These distal DMRs were highly associated with the H3K27ac chromatin mark in both LGR $^{+}$and differentiated cells (Fig. 6B). Hes1 is well known as a target of Notch signaling through RBP-J sites found in the proximal promoter (Jarriault et al. 1995). Additionally, cis-regulatory modules found in likely Hes 1 enhancers have also been shown to be important in the regulation of Hes 1 expression and contain predicted RBPJ-binding sites (Jeziorska et al. 2012). Interestingly, one of these cis-regulatory modules is located within our $-9-\mathrm{kb}$ DMR and is bound by $\mathrm{Cdx} 2$ and $\mathrm{Hnf} 4 \alpha$ in villous cells, suggesting that this region is actively recruiting intestinal transcription factors (Fig. 6B).

Having established that DNA methylation is indeed dynamic at specific and relevant regulatory regions in the genome during the transition from stem to fully mature, differentiated epithelial cells, we investigated ISC genes that showed methylation differences between LGR $5^{+}$stem and differentiated cells in the Dnmt1 $1^{\text {lox/lox }}$; Villin-CreERT2 intestine. As predicted, Olfm4 and Hes1 showed an expanded expression domain in the mutant intestine (Fig. 7A,B,D,E). These data prompted us to examine the methylation status at the DMRs associated with Olfm4 and Hes1. Due to the temporal delay between altered DNA methylation on gene expression, we examined DNA from mutant and control mice $2 \mathrm{~d}$ before the most severe crypt expansion was manifested. At this time point, we already detected increased mRNA levels of both Hes1 and Olfm 4 (Fig. 7C,F). Strikingly, mutants showed a 10\% decrease of methylation at both genes (Fig. 7G,H). while methylation at the H19 imprinted locus was not affected in Dnmt1 mutant mice (Supplemental Fig. 7B). These data demonstrate that Dnmt1 is required in intestinal crypts for the increase in methylation between ISCs and differentiated cells at intestinal specific loci and not just for maintenance of global DNA methylation patterns in the adult intestine.

\section{Discussion}

Our study shows that DNA methylation changes significantly and at relevant sites during the 3- to 5-d transition from cycling stem to differentiated intestinal epithelial cells and is required for the appropriate timing of differentiation. Our genome-wide approaches, integrating data on DNA methylation, histone marks, transcription factor binding, and mRNA expression profiling, allowed us to define new regulatory regions that are differentially methylated during intestinal epithelial differentiation and are associated with the control of critical intestinal genes. These genome and genetic data demonstrate that gene expression changes of essential intestinal genes 


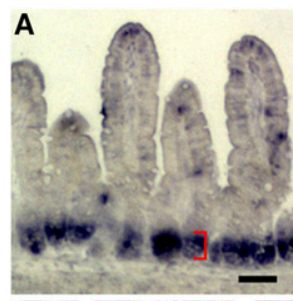

B 10 C
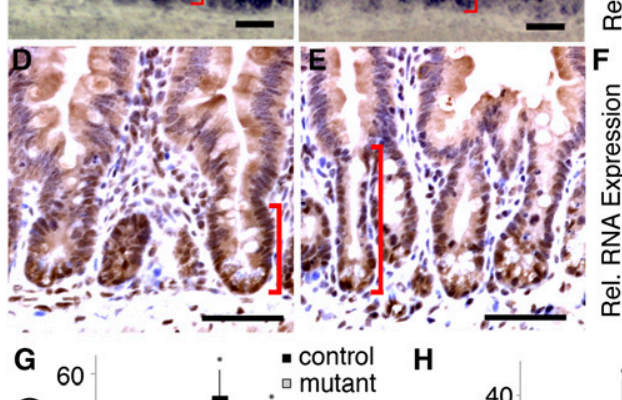

H


Figure 7. Loss of DNMT1 causes activation of Olfm4 and Hes1. $(A, B)$ In situ hybridization of Olfm4 shows increased RNA expression zone in intestinal crypts of mutant $(B)$ compared with control $(A)$ mice. Bars, $50 \mu \mathrm{m}$. $(C)$ Olfm4 mRNA expression analysis by qRT-PCR shows increased expression in mutant intestinal epithelial cells. mRNA levels are expressed relative to those of Gapdh. Mean $\pm \mathrm{SE} ; n \geq 4 ;\left({ }^{*}\right) P=0.05$ by $t$-test. $(D, E)$ Hes 1 protein expression in control $(D)$ and mutant (E) intestine as detected by immunohistochemistry. (F) Hes1 mRNA expression analysis by qRT-PCR shows increased expression in mutant intestinal epithelial cells. Data are relative to Gapdh, mean $\pm \mathrm{SE}_{;} n \geq 4$; $\left(^{\star}\right) P<0.05$ by $t$-test. $(G, H)$ Pyrosequencing reveals a $10 \%$ decrease in average methylation of LMR-129189 (Olfm4) (G) and UMR-138988 (Hes1) (H) in mutant intestinal epithelia compared with control. Methylation at each $\mathrm{CpG}$ and the region average are shown. Data are mean \pm SE; $n \geq 6 ;\left({ }^{*}\right) P<0.05$ by $t$-test. (I) Proposed model of coordination of gene expression during intestinal differentiation. LGR $^{+}$stem cells $\left(\right.$LGR $^{+}$ISC), differentiated intestinal epithelial cells (DIFF IEC), and mutant intestinal epithelium ( $\triangle \mathrm{DNMT1})$. Genes highly expressed in LGR5 ${ }^{+}$ISCs, such as Olfm4 and Hes1, gain methylation in DIFF intestinal epithelial cells, and expression is repressed. Intestinal enterocyte genes Alpi and Lct are demethylated in DIFF intestinal epithelial cells and bound by Cdx-1 and $\mathrm{HNF} 4 \alpha$, and expression is activated. Loss of Dnmt 1 causes hypomethylation and increased expression of Olfm4 and Hes1. during differentiation are in part controlled by DNA methylation. Many of the DMRs identified by this study are located outside of proximal gene promoters or $\mathrm{CpG}$ islands and have not been previously implicated in the regulation of gene expression. Based on the H3K27ac chromatin modification dynamics and the association of multiple intestinal-specific transcription factors, many of these DMRs are likely active intestinal enhancers. During differentiation, enhancer regions associated with genes important for enterocyte differentiation, such as Alpi and Lct, are demethylated, coordinating the binding of transcription factors, such as $\mathrm{Cdx} 2$ and $\mathrm{Hnf} 4 \alpha$, with the activation of gene expression (Fig. 7I). Concurrently, DNA methylation increases at ISC enhancers, such as those of Olfm4 and Hes1, correlating with repression of the corresponding genes (Fig. 7I). Loss of maintenance methylation by Dnmt1 causes increased ISC gene expression due to enhancer hypomethylation, which may allow for inappropriate binding of transcription factors, such as $\mathrm{Cdx} 2$, thus blocking progression through differentiation (Fig. 7I). ISC gene expression is eventually attenuated, presumably due to loss of exposure to signaling factors critical for stem cell maintenance, such as Wnt and Notch, as cells move up the crypt-villus axis.

ISC gene expression depends critically on complex combinations of signaling pathways and transcription factors (Sheaffer and Kaestner 2012). Deletion of Wnt or Notch signaling components causes loss of the intestinal epithelium through failure of self-renewal of ISCs and appropriate differentiation (Korinek et al. 1998; Pellegrinet et al. 2011; Ueo et al. 2012; van Es et al. 2012; VanDussen et al. 2012). Conversely, increased activation of Wnt and Notch signaling causes expansion of the ISC niche and disrupted differentiation (Moser et al. 1990; Stanger et al. 2005; Zecchini et al. 2005). In coordination with these signaling pathways, transcription factors such as the $\mathrm{Cdx}$ proteins are required for expression of ISC genes, and genetic ablation of Cdx1 and Cdx2 causes total loss of the epithelium (Gao et al. 2009; Gao and Kaestner 2010; Verzi et al. 2011). Furthermore, in human intestinal Caco-2 cells, Cdx2 binding is associated with ISC genes in the undifferentiated state, and its binding profile overlaps with Tcf4, the major Wnt effector (Verzi et al. 2010). Our DMRs show high overlap with the Cdx2 ChIP-seq binding profile (Verzi et al. 2013). Our data set will be a useful resource for further work to determine which role DNA methylation plays in the coordination of signaling pathways and transcription factor binding, such as Wnt and $\mathrm{Cdx} 2$, to activate gene expression during normal intestinal differentiation.

Changes in DNA methylation during intestinal differentiation may be important for the combinational control of gene expression by modulating chromatin accessibility for multiple transcription factors. DMRs were enriched for the predicted binding sites of multiple transcription factors, including Cdx2, GATA, Hnf $1 \alpha$, and $\operatorname{Hnf} 4 \alpha$, which act in combination to control gene activation during intestinal differentiation (Benoit et al. 2010; Verzi et al. 2013). Transcription factor binding is important to main- 
tain DNA hypomethylation and chromatin accessibility at enhancers in both mouse and human cells (Palacios et al. 2010; Stadler et al. 2011; Thurman et al. 2012). In support of these findings, we show that after intestinal differentiation, regions that have reduced DNA methylation are occupied by multiple transcription factors. However, our data also suggest that DNA methylation is critical for appropriate timing of gene repression and may not simply play a passive role in response to transcription factor binding. Similarly, genetic deletions of Dnmt3a and Dnmt1 in the hematopoietic stem cell reveal that DNA methylation is required for silencing of hematopoietic stem cell genes (Trowbridge et al. 2009; Challen et al. 2012). In addition, our data establish a role for DNA methylation in the terminal repression of ISC genes. Thus, DNA methylation may initiate gene repression by imposing changes in chromatin that antagonize transcription factor binding to enhancers. More studies are needed to show whether DNA methylation controls accessibility of direct effectors of Wnt and Notch signaling, such as Tcf4 and RBP-J, to enhancers after intestinal differentiation in vivo.

In summary, we demonstrate that maintenance of DNA methylation by Dnmt1 is required for the repression of ISC genes to allow appropriate timing of differentiation. DNA methylation is dynamic at many relevant regulatory elements during intestinal epithelial differentiation. Our data suggest that DNA methylation plays an active role in the regulation of gene expression by controlling accessibility of enhancers during intestinal epithelial differentiation.

\section{Materials and methods}

Mice

$D n m t 1^{\text {lox/lox }}$ mice were provided by Rudolf Jaenisch (JacksonGrusby et al. 2001), and Villin-Cre-ERT2 mice were received from Sylvia Robine (el Marjou et al. 2004). For genome-wide analysis, cells were isolated from mice on the $\mathrm{C} 57 \mathrm{Bl} / 6$ background and Lgr5-EGFP-ires-CreERT2 transgenic mice (Barker et al. 2007). For Dnmt1 deletion experiments, Cre recombination was induced by three daily oral administrations of $1.6 \mathrm{mg}$ of tamoxifen (Sigma) in an ethanol/sunflower oil mixture and littermate controls without the Cre-ERT2 transgene plus tamoxifen treatment. All procedures involving mice were conducted in accordance with approved Institutional Animal Care and Use Committee protocols.

\section{Intestinal epithelium isolation and FACS}

Small intestines were opened longitudinally and washed in PBS. Villous epithelial cells were removed by gentle scraping with a coverslip. The intestine was cut into $1-\mathrm{mm}$ pieces and incubated in $5 \mathrm{mM}$ EDTA in HBSS for $35 \mathrm{~min}$, and the epithelial cell layer was isolated by manual pipetting and collected for whole-intestine analysis or passed through a $70-\mu \mathrm{m}$ filter to isolate crypts. Crypts were dissociated into single cells using $0.05 \%$ trypsin (HyClone), and GFP-positive cells that were confirmed as viable by DAPI were isolated using FACS performed on the FACSVAntage SE (BD Biosciences). Cells were immediately frozen in liquid nitrogen. DNA and RNA were isolated using the AllPrep Qiagen kit (Qiagen).
DNA methylome analysis

WGSBS was performed as previously published (Lister et al. 2009) with the following changes. Isolated genomic DNA was fragmented into $\approx 300$-bp pieces using the S220 focused ultrasonicator (Covaris). Sequencing libraries were generated with $\geq 500 \mathrm{ng}$ of genomic DNA using the NEBNext genomic sequencing kit (New England Biolabs) and Illumina adaptors (PE-102-1001 and PE-1021002). Libraries were bisulfite-converted using the Imprint DNA modification kit (Sigma). Size selection of the libraries to 300-600 base pairs (bp) was performed on the Pippin Prep DNA size selection system (Sage Science). Amplification of libraries was performed in 18 rounds of PCR using Pfu Turbo Cx Hotstart DNA polymerase (Agilent Technologies). Paired-end sequencing was performed on the Illumina HiSeq (100-bp reads).

Converted DNA sequence was aligned to the mouse $(\mathrm{mm} 9)$ genome using BS Seeker (Chen et al. 2010). Percent methylation was calculated for individual Cs as the ratio of the number of alignments with $\mathrm{C}$ (methylated) over the number of alignments with either $\mathrm{C}$ or $\mathrm{T}$. Data from the $\mathrm{C}$ and adjacent $\mathrm{G}$ were combined to represent each $\mathrm{CpG}$. Segmentation was performed as described previously using the $\mathrm{R}$ package RHmm, with a three-state HMM corresponding to fully methylated $(>50 \%)$, low-methylated $(13.9 \%-50 \%)$, and unmethylated $(<13.9 \%)$ CpGs (Stadler et al. 2011). Due to increased variability in single-CpG methylation levels in FMRs compared with the ESCs and neural progenitor methylomes analyzed in Stadler et al. (2011), methylation levels were smoothed over five CpGs prior to HMM segmentation.

DMRs were determined using a Bayesian binomial model (Berninger et al. 2008). To determine DMRs, we first determined a joint set of segments, which is the union of all segments (UMRs or LMRs) identified in either cell type. In case two or more segments overlapped, the segments were fused into one longer segment containing all nucleotides of the overlapping segments. We then determined for each segment (in the joint set) its methylated and total counts in each methylome by summing the counts over all reads mapping to the segment. The potential DMRs had a median of seven and a mean of 16 CpGs. To assess whether methylation levels were significantly different between the methylomes, we used a Bayesian binomial model that considers two hypotheses: the hypothesis that the average methylation levels of the segments are the same (H1) versus the hypothesis that the average methylation levels in the two methylomes can take on any value and are independent of each other (H2) (see Berninger et al. 2008, for details of the calculation). We used a conservative Bonferroni correction of 162,891 to the posterior probability for $\mathrm{H} 2$ and accepted regions as DMRs when the corrected posterior probability of $\mathrm{H} 1$ was $<0.1$. This type of correction is judged appropriate for large numbers of independent tests when the null hypothesis is the favored hypothesis; i.e., that most regions are not DMRs (Westfall 1997). These significant regions had a median of 14 and a mean of $23 \mathrm{CpGs}$ and thus have a strong statistical foundation.

\section{mRNA expression analysis}

mRNA expression was measured using qRT-PCR, as previously described (Gupta et al. 2007). Primer sets can be found in the Supplemental Material (Supplemental Table 5). RNA sequencing libraries were constructed from $\geq 200 \mu \mathrm{g}$ of total RNA isolated using the TruSeq RNA sample prep kit (Illumina). Single-read sequencing was performed on an Illumina hiSeq2000 (100-bp reads). Reads were aligned to the mouse reference genome (NCBI build 37, mm9) using TopHat (Trapnell et al. 2012). TopHat was run with the University of California at Santa Cruz refFlat 
annotation file (GTF format) and the "-no-novel-juncs" option to map reads only in the reference annotation. With three biological replicates, gene expression levels were calculated by Cuffdiff (Trapnell et al. 2012) using the same reference annotation file. mRNA levels were expressed in reads per kilobase of transcript per million mapped reads (RPKM).

\section{Pathway and motif analysis}

The pathway analyses were generated through the use of Ingenuity Pathway Analysis (IPA; Ingenuity Systems, http:// www.ingenuity.com). De novo motif analyses were performed using HOMER (Heinz et al. 2010).

\section{Histological procedures and in situ hybridization}

Tissues were isolated and fixed using $4 \%$ paraformaldehyde and then embedded in paraffin. Antigen retrieval was performed using the 2100 Antigen Retriever in buffer A (Electron Microscopy Sciences), and standard immunostaining procedures were performed for Dnmt1 (Santa Cruz Biotechnology), Chga (Immunostar), Dnmt3a (Santa Cruz Biotechnology), Dnmt3b (Abcam), E-Cadherin (BD Transduction Laboratories), Sox9 (Millipore), Lyz (Dako), Ki67 (BD Pharmingen), and Muc2 (Santa Cruz Biotechnology). Immunohistochemical procedures were modified for Hes-1 (Ben Stanger, University of Pennsylvania), including antigen retrieval in high-pH antigen unmasking solution (Vector Laboratories) and signal amplification with the TSA Fluorescein system (Perkin Elmer). AP staining was performed using NBT and BCIP (Boehringer Ingelheim). In situ hybridization for Olfm4 was performed as described previously (Barker et al. 2007). All microscopy was performed on the Nikon Eclipse 80i.

\section{Pyrosequencing and bisulfite sequencing}

One-hundred nanograms of DNA was bisulfite-converted using the Epitect bisulfite kit (Qiagen). Pyrosequencing assays were designed using Pyromark assay design software (Qiagen). For pyrosequencing, template DNA was amplified using the Pyromark PCR kit (Qiagen), and sequencing was performed using the PyroMark Q96 ID (Qiagen). For bisulfite sequencing, template DNA was amplified using KAPA HIFI Uracil ${ }^{+}$(KAPA), sequencing libraries were made using the Ovation SP ultralow library system and Mondrian $\mathrm{SP}^{+}$Workstation (NuGEN), and 150-bp paired-end sequencing was performed on the MiSeq (Illumina). Converted sequences were aligned to the mouse genome $(\mathrm{mm} 9)$ using BS Seeker (Chen et al. 2010). Primer sets can be found in the Supplemental Material (Supplemental Table 6).

\section{ChIP analysis}

LGR $^{+}$and differentiated cells were isolated and incubated in $1.11 \%$ formaldehyde for $10 \mathrm{~min}$ at room temperature. Chromatin was sonicated into 200- to 300-bp fragments using the BioRuptor (Diagenode). Immunoprecipitation was performed using $2 \mu \mathrm{g}$ of H3K27ac antibody (Active Motif) and $2 \mu \mathrm{g}$ of chromatin for two biological replicates for each cell type. ChIPseq libraries were made using the ChIP-seq Library Prep reagent set (New England Biolabs). Paired-end sequencing was performed on the hiSeq2000 (50-bp reads). Multiplexed libraries for H2K27ac chromatin-immunoprecipitated chromatin and input DNA were sequenced to 50-bp single reads on an Illumina hiSeq2500 in rapid-run mode. Reads were aligned to the genome using Bowtie (-k 1 -m 1-best-strata). Peaks were called using HOMER in histone mode and with PCR duplicates discarded. Regions were selected with a false discovery rate cutoff of $1 \%$.

\section{Data access}

All WGSBS, RNA sequencing, and ChIP-seq data generated in this study have been deposited in ArrayExpress under accession number E-MTAB-2350.

\section{Acknowledgments}

We thank Marisa Bartolomei, Dana Avrahami, and Nuria Bramswig for helpful comments, and Alan Fox, Olga Smirnova, Joe Grubb, Shilpa Rao, Chris Krapp for technical assistance. We thank Paul Halberg and Charles Pletcher for FACS analysis. This work was supported by National Institutes of Health grants R37DK053839 to K.H.K. and T32 HD751613 to K.L.S.

\section{References}

Barker N, van Es JH, Kuipers J, Kujala P, van den Born M, Cozijnsen M, Haegebarth A, Korving J, Begthel H, Peters PJ, et al. 2007. Identification of stem cells in small intestine and colon by marker gene Lgr5. Nature 449: 1003-1007.

Barker N, Ridgway RA, van Es JH, van de Wetering $M$, Begthel $\mathrm{H}$, van den Born M, Danenberg E, Clarke AR, Sansom OJ, Clevers H. 2009. Crypt stem cells as the cells-of-origin of intestinal cancer. Nature 457: 608-611.

Benoit YD, Pare F, Francoeur C, Jean D, Tremblay E, Boudreau F, Escaffit F, Beaulieu JF. 2010. Cooperation between HNF-1 $\alpha$, $\mathrm{Cdx} 2$, and GATA-4 in initiating an enterocytic differentiation program in a normal human intestinal epithelial progenitor cell line. Am J Physiol Gastrointest Liver Physiol 298: G504-G517.

Berninger P, Gaidatzis D, van Nimwegen E, Zavolan M. 2008. Computational analysis of small RNA cloning data. Methods 44: 13-21.

Beuling E, Baffour-Awuah NY, Stapleton KA, Aronson BE, Noah TK, Shroyer NF, Duncan SA, Fleet JC, Krasinski SD. 2011. GATA factors regulate proliferation, differentiation, and gene expression in small intestine of mature mice. Gastroenterology 140: 1219-1229.e1-2.

Broske AM, Vockentanz L, Kharazi S, Huska MR, Mancini E, Scheller M, Kuhl C, Enns A, Prinz M, Jaenisch R, et al. 2009. DNA methylation protects hematopoietic stem cell multipotency from myeloerythroid restriction. Nat Genet 41: 1207-1215.

Cavicchi M, Whittle BJ. 1999. Regulation of induction of nitric oxide synthase and the inhibitory actions of dexamethasone in the human intestinal epithelial cell line, Caco-2: influence of cell differentiation. Br J Pharmacol 128: 705-715.

Challen GA, Sun D, Jeong M, Luo M, Jelinek J, Berg JS, Bock C, Vasanthakumar A, Gu H, Xi Y, et al. 2012. Dnmt3a is essential for hematopoietic stem cell differentiation. Nat Genet 44: 23-31.

Chen PY, Cokus SJ, Pellegrini M. 2010. BS Seeker: precise mapping for bisulfite sequencing. BMC Bioinformatics 11: 203.

D'Angelo A, Bluteau O, Garcia-Gonzalez MA, Gresh L, Doyen A, Garbay S, Robine S, Pontoglio M. 2010. Hepatocyte nuclear factor $1 \alpha$ and $\beta$ control terminal differentiation and cell fate commitment in the gut epithelium. Development 137: 15731582 .

Duranton B, Keith G, Gossé F, Bergmann C, Schleiffer R, Raul F. 1998. Concomitant changes in polyamine pools and DNA methylation during growth inhibition of human colonic cancer cells. Exp Cell Res 243: 319-325.

Dusing MR, Maier EA, Aronow BJ, Wiginton DA. 2010. Onecut-2 knockout mice fail to thrive during early postnatal period and have altered patterns of gene expression in small intestine. Physiol Genomics 42: 115-125. 
el Marjou F, Janssen KP, Chang BH, Li M, Hindie V, Chan L, Louvard D, Chambon P, Metzger D, Robine S. 2004. Tissuespecific and inducible Cre-mediated recombination in the gut epithelium. Genesis 39: 186-193.

Formeister EJ, Sionas AL, Lorance DK, Barkley CL, Lee GH, Magness ST. 2009. Distinct SOX9 levels differentially mark stem/progenitor populations and enteroendocrine cells of the small intestine epithelium. Am I Physiol Gastrointest Liver Physiol 296: G1108-G1118.

Gao N, Kaestner KH. 2010. Cdx2 regulates endo-lysosomal function and epithelial cell polarity. Genes Dev 24: 1295-1305.

Gao N, White P, Kaestner KH. 2009. Establishment of intestinal identity and epithelial-mesenchymal signaling by Cdx2. Dev Cell 16: 588-599.

Garrison WD, Battle MA, Yang C, Kaestner KH, Sladek FM, Duncan SA. 2006. Hepatocyte nuclear factor $4 \alpha$ is essential for embryonic development of the mouse colon. Gastroenterology 130: 1207-1220.

Gershon MD. 2004. Review article: serotonin receptors and transporters-roles in normal and abnormal gastrointestinal motility. Aliment Pharmacol Ther 20: 3-14.

Gupta RK, Gao N, Gorski RK, White P, Hardy OT, Rafiq K, Brestelli JE, Chen G, Stoeckert CJ Jr, Kaestner KH. 2007. Expansion of adult $\beta$-cell mass in response to increased metabolic demand is dependent on HNF-4 $\alpha$. Genes Dev 21: 756-769.

Harrison EH. 2005. Mechanisms of digestion and absorption of dietary vitamin A. Annu Rev Nutr 25: 87-103.

Hattori N, Abe T, Suzuki M, Matsuyama T, Yoshida S, Li E, Shiota K. 2004. Preference of DNA methyltransferases for CpG islands in mouse embryonic stem cells. Genome Res 14: 1733-1740.

Heinz S, Benner C, Spann N, Bertolino E, Lin YC, Laslo P, Cheng JX, Murre C, Singh H, Glass CK. 2010. Simple combinations of lineage-determining transcription factors prime cisregulatory elements required for macrophage and $\mathrm{B}$ cell identities. Mol Cell 38: 576-589.

Huang Y, Yang M, Yang H, Zeng Z. 2010. Upregulation of the GRIM-19 gene suppresses invasion and metastasis of human gastric cancer SGC-7901 cell line. Exp Cell Res 316: 20612070.

Jackson-Grusby L, Beard C, Possemato R, Tudor M, Fambrough D, Csankovszki G, Dausman J, Lee P, Wilson C, Lander E, et al. 2001. Loss of genomic methylation causes p53dependent apoptosis and epigenetic deregulation. Nat Genet 27: 31-39.

Jarriault S, Brou C, Logeat F, Schroeter EH, Kopan R, Israel A. 1995. Signalling downstream of activated mammalian Notch. Nature 377: 355-358.

Jeziorska DM, Koentges G, Vance KW. 2012. Novel cis-regulatory modules control expression of the Hairy and Enhancer of Split-1 (HES1) transcription factor in myoblasts. J Biol Chem 287: 5687-5697.

Kaaij LT, van de Wetering M, Fang F, Decato B, Molaro A, van de Werken HJ, van Es JH, Schuijers J, de Wit E, de Laat W, et al. 2013. DNA methylation dynamics during intestinal stem cell differentiation reveals enhancers driving gene expression in the villus. Genome Biol 14: R50.

Kim K, Doi A, Wen B, Ng K, Zhao R, Cahan P, Kim J, Aryee MJ, Ji H, Ehrlich LI, et al. 2010a. Epigenetic memory in induced pluripotent stem cells. Nature 467: 285-290.

Kim KK, Park KS, Song SB, Kim KE. 2010b. Up regulation of GW112 Gene by NF $\kappa$ B promotes an antiapoptotic property in gastric cancer cells. Mol Carcinog 49: 259-270.

Korinek V, Barker N, Moerer P, van Donselaar E, Huls G, Peters PJ, Clevers H. 1998. Depletion of epithelial stem-cell com- partments in the small intestine of mice lacking Tcf-4. Nat Genet 19: 379-383.

Lee PP, Fitzpatrick DR, Beard C, Jessup HK, Lehar S, Makar KW, Perez-Melgosa M, Sweetser MT, Schlissel MS, Nguyen S, et al. 2001. A critical role for Dnmt1 and DNA methylation in T cell development, function, and survival. Immunity 15: 763-774.

Lei H, Oh SP, Okano M, Juttermann R, Goss KA, Jaenisch R, Li E. 1996. De novo DNA cytosine methyltransferase activities in mouse embryonic stem cells. Development 122: 3195-3205.

Li E, Bestor TH, Jaenisch R. 1992. Targeted mutation of the DNA methyltransferase gene results in embryonic lethality. Cell 69: 915-926.

Liang G, Chan MF, Tomigahara Y, Tsai YC, Gonzales FA, Li E, Laird PW, Jones PA. 2002. Cooperativity between DNA methyltransferases in the maintenance methylation of repetitive elements. Mol Cell Biol 22: 480-491.

Lister R, Pelizzola M, Dowen RH, Hawkins RD, Hon G, TontiFilippini J, Nery JR, Lee L, Ye Z, Ngo QM, et al. 2009. Human DNA methylomes at base resolution show widespread epigenomic differences. Nature 462: 315-322.

Liu W, Lee HW, Liu Y, Wang R, Rodgers GP. 2010. Olfactomedin 4 is a novel target gene of retinoic acids and 5-aza-2'deoxycytidine involved in human myeloid leukemia cell growth, differentiation, and apoptosis. Blood 116: 49384947.

Lussier CR, Brial F, Roy SA, Langlois MJ, Verdu EF, Rivard N, Perreault N, Boudreau F. 2010. Loss of hepatocyte-nuclearfactor-1 $\alpha$ impacts on adult mouse intestinal epithelial cell growth and cell lineages differentiation. PLOS ONE 5: e12378.

Moser AR, Pitot HC, Dove WF. 1990. A dominant mutation that predisposes to multiple intestinal neoplasia in the mouse. Science 247: 322-324.

Munoz J, Stange DE, Schepers AG, van de Wetering M, Koo BK, Itzkovitz S, Volckmann R, Kung KS, Koster J, Radulescu S, et al. 2012. The Lgr5 intestinal stem cell signature: robust expression of proposed quiescent ' +4 ' cell markers. EMBO $J$ 31: 3079-3091.

Noah TK, Shroyer NF. 2013. Notch in the intestine: regulation of homeostasis and pathogenesis. Annu Rev Physiol 75: 263-288.

Okano M, Bell DW, Haber DA, Li E. 1999. DNA methyltransferases Dnmt3a and Dnmt3b are essential for de novo methylation and mammalian development. Cell 99: 247257.

Palacios D, Summerbell D, Rigby PW, Boyes J. 2010. Interplay between DNA methylation and transcription factor availability: implications for developmental activation of the mouse Myogenin gene. Mol Cell Biol 30: 3805-3815.

Pan X, Hussain MM. 2012. Gut triglyceride production. Biochim Biophys Acta 1821: 727-735.

Pellegrinet L, Rodilla V, Liu Z, Chen S, Koch U, Espinosa L, Kaestner KH, Kopan R, Lewis J, Radtke F. 2011. Dll1- and dll4-mediated notch signaling are required for homeostasis of intestinal stem cells. Gastroenterology 140: 1230-1240.e1-7.

Polo JM, Liu S, Figueroa ME, Kulalert W, Eminli S, Tan KY, Apostolou E, Stadtfeld M, Li Y, Shioda T, et al. 2010. Cell type of origin influences the molecular and functional properties of mouse induced pluripotent stem cells. Nat Biotechnol 28: 848-855.

Potten CS, Booth C, Tudor GL, Booth D, Brady G, Hurley P, Ashton G, Clarke R, Sakakibara S, Okano H. 2003. Identification of a putative intestinal stem cell and early lineage marker; musashi-1. Differentiation 71: 28-41.

Sakamori R, Das S, Yu S, Feng S, Stypulkowski E, Guan Y, Douard V, Tang W, Ferraris RP, Harada A, et al. 2012. Cdc42 
and Rab8a are critical for intestinal stem cell division, survival, and differentiation in mice. I Clin Invest 122: $1052-1065$.

Schepers A, Clevers H. 2012. Wnt signaling, stem cells, and cancer of the gastrointestinal tract. Cold Spring Harb Perspect Biol 4: a007989.

Schmidt CS, Bultmann S, Meilinger D, Zacher B, Tresch A, Maier KC, Peter C, Martin DE, Leonhardt H, Spada F. 2012. Global DNA hypomethylation prevents consolidation of differentiation programs and allows reversion to the embryonic stem cell state. PLOS ONE 7: e52629.

Schneider MR, Dahlhoff M, Horst D, Hirschi B, Trulzsch K, Muller-Hocker J, Vogelmann R, Allgauer M, Gerhard M, Steininger S, et al. 2010. A key role for E-cadherin in intestinal homeostasis and Paneth cell maturation. PLOS ONE 5: e14325.

Sen GL, Reuter JA, Webster DE, Zhu L, Khavari PA. 2010. DNMT1 maintains progenitor function in self-renewing somatic tissue. Nature 463: 563-567.

Sheaffer KL, Kaestner KH. 2012. Transcriptional networks in liver and intestinal development. Cold Spring Harb Perspect Biol 4: a008284.

Smith ZD, Meissner A. 2013. DNA methylation: roles in mammalian development. Nat Rev Genet 14: 204-220.

Stadler MB, Murr R, Burger L, Ivanek R, Lienert F, Scholer A, van Nimwegen E, Wirbelauer C, Oakeley EJ, Gaidatzis D, et al. 2011. DNA-binding factors shape the mouse methylome at distal regulatory regions. Nature 480: 490-495.

Stanger BZ, Datar R, Murtaugh LC, Melton DA. 2005. Direct regulation of intestinal fate by Notch. Proc Natl Acad Sci 102: $12443-12448$.

Stappenbeck TS, Gordon JI. 2000. Racl mutations produce aberrant epithelial differentiation in the developing and adult mouse small intestine. Development 127: 2629-2642.

Stegmann A, Hansen M, Wang Y, Larsen JB, Lund LR, Ritie L, Nicholson JK, Quistorff B, Simon-Assmann P, Troelsen JT, et al. 2006. Metabolome, transcriptome, and bioinformatic cis-element analyses point to HNF-4 as a central regulator of gene expression during enterocyte differentiation. Physiol Genomics 27: 141-155.

Steine EJ, Ehrich M, Bell GW, Raj A, Reddy S, van Oudenaarden A, Jaenisch R, Linhart HG. 2011. Genes methylated by DNA methyltransferase $3 \mathrm{~b}$ are similar in mouse intestine and human colon cancer. J Clin Invest 121: 1748-1752.

Suetake L, Shi L, Watanabe D, Nakamura M, Tajima S. 2001 Proliferation stage-dependent expression of DNA methyltransferase (Dnmt1) in mouse small intestine. Cell Struct Funct 26: $79-86$.

Thurman RE, Rynes E, Humbert R, Vierstra J, Maurano MT, Haugen E, Sheffield NC, Stergachis AB, Wang H, Vernot B, et al. 2012. The accessible chromatin landscape of the human genome. Nature 489: 75-82.

Trapnell C, Roberts A, Goff L, Pertea G, Kim D, Kelley DR, Pimentel H, Salzberg SL, Rinn JL, Pachter L. 2012. Differential gene and transcript expression analysis of RNA-seq experiments with TopHat and Cufflinks. Nat Protoc 7: 562-578.

Trowbridge JJ, Snow JW, Kim J, Orkin SH. 2009. DNA methyltransferase 1 is essential for and uniquely regulates hematopoietic stem and progenitor cells. Cell Stem Cell 5: 442-449.

Ueo T, Imayoshi I, Kobayashi T, Ohtsuka T, Seno H, Nakase H, Chiba T, Kageyama R. 2012. The role of Hes genes in intestinal development, homeostasis and tumor formation. Development 139: 1071-1082.

van der Flier LG, Clevers H. 2009. Stem cells, self-renewal, and differentiation in the intestinal epithelium. Annu Rev Physiol 71: 241-260. van Es JH, Sato T, van de Wetering M, Lyubimova A, Nee AN, Gregorieff A, Sasaki N, Zeinstra L, van den Born M, Korving J, et al. 2012. Dll1 ${ }^{+}$secretory progenitor cells revert to stem cells upon crypt damage. Nat Cell Biol 14: 1099-1104.

VanDussen KL, Carulli AJ, Keeley TM, Patel SR, Puthoff BJ, Magness ST, Tran IT, Maillard I, Siebel C, Kolterud A, et al. 2012. Notch signaling modulates proliferation and differentiation of intestinal crypt base columnar stem cells. Development 139: 488-497.

Verzi MP, Hatzis P, Sulahian R, Philips J, Schuijers J, Shin H, Freed E, Lynch JP, Dang DT, Brown M, et al. 2010. TCF4 and CDX2, major transcription factors for intestinal function, converge on the same cis-regulatory regions. Proc Natl Acad Sci 107: 15157-15162.

Verzi MP, Shin H, Ho LL, Liu XS, Shivdasani RA. 2011. Essential and redundant functions of caudal family proteins in activating adult intestinal genes. Mol Cell Biol 31: 2026-2039.

Verzi MP, Shin H, San Roman AK, Liu XS, Shivdasani RA. 2013. Intestinal master transcription factor CDX2 controls chromatin access for partner transcription factor binding. Mol Cell Biol 33: 281-292.

Wang Z, Chen J, Sun J, Cui Z, Wu H. 2012. RNA interferencemediated silencing of eukaryotic translation initiation factor 3 , subunit B (EIF3B) gene expression inhibits proliferation of colon cancer cells. World J Surg Oncol 10: 119.

Westfall PH. 1997. A Bayesian perspective on the Bonferroni adjustment. Biometrika 84: 419-427.

Ye DZ, Kaestner KH. 2009. Foxa1 and Foxa2 control the differentiation of goblet and enteroendocrine L- and D-cells in mice. Gastroenterology 137: 2052-2062.

Yeung TM, Chia LA, Kosinski CM, Kuo CJ. 2011. Regulation of self-renewal and differentiation by the intestinal stem cell niche. Cell Mol Life Sci 68: 2513-2523.

Zecchini V, Domaschenz R, Winton D, Jones P. 2005. Notch signaling regulates the differentiation of post-mitotic intestinal epithelial cells. Genes Dev 19: 1686-1691. 


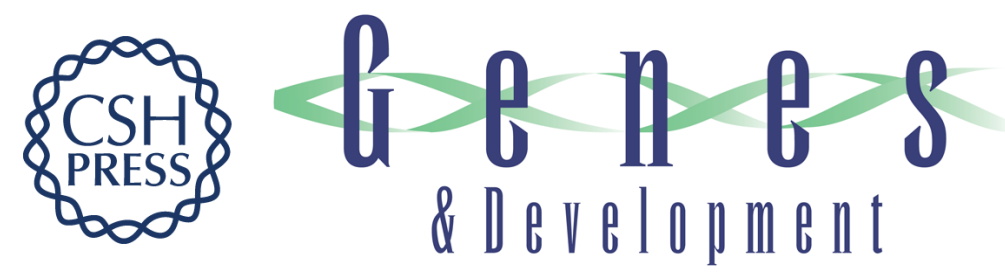

\section{DNA methylation is required for the control of stem cell differentiation in the small intestine}

Karyn L. Sheaffer, Rinho Kim, Reina Aoki, et al.

Genes Dev. 2014, 28:

Access the most recent version at doi:10.1101/gad.230318.113

\section{Supplemental http://genesdev.cshlp.org/content/suppl/2014/03/13/28.6.652.DC1 Material}

References This article cites 74 articles, 21 of which can be accessed free at: http://genesdev.cshlp.org/content/28/6/652.full.html\#ref-list-1

Creative This article is distributed exclusively by Cold Spring Harbor Laboratory Press for the first Commons six months after the full-issue publication date (see

License http://genesdev.cshlp.org/site/misc/terms.xhtml). After six months, it is available under a Creative Commons License (Attribution-NonCommercial 4.0 International), as described at http://creativecommons.org/licenses/by-nc/4.0/.

Email Alerting Receive free email alerts when new articles cite this article - sign up in the box at the top Service right corner of the article or click here.

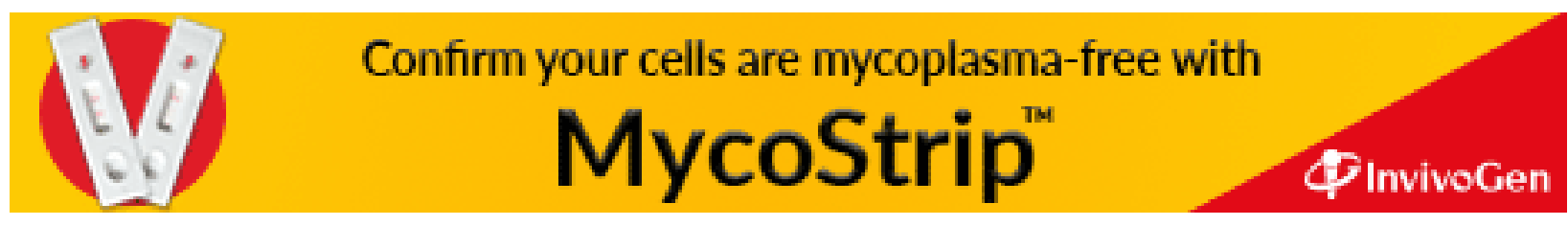

